\title{
Assessment of awareness on food borne zoonosis and its relation with Veterinary Public Health Services in and around Addis Ababa, Ethiopia
}

\author{
Sisay Girma1, Girma Zewde ${ }^{2}$,Ketema Tafess ${ }^{3}$, Tariku Jibat ${ }^{2 *}$. \\ ${ }^{1}$ Haramaya University, College of Veterinary Medicine, P.O.Box 138, Dire Dawa, Ethiopia \\ ${ }^{2}$ Addis Ababa University, School of Veterinary Medicine, P.O. Box 34, Debre Zeit, Ethiopia. \\ ${ }^{3}$ University of Gondar, College of medical Sciences, P.O.Box 196, Gondar, Ethiopia \\ *Corresponding author: E mail tarikuj@yahoo.com
}

\begin{abstract}
A survey qualitative survey was conducted to assess the awareness on food borne zoonosis and its relation with Veterinary Public Health Services in Addis Ababa and its surrounding districts from November 2008 to May 2009. Structured questionnaire was used in the study. Questionnaires were distributed to 384 individuals, of which 196 were elementary and high school students, and 196 were Graduates. Factors like education level, information source and profession were considered for possible explanation of the results. The use of inspected animal products is found statistically different $(\mathrm{P}<0.05)$ among health and non health professionals while no difference is seen between students and graduates. The majority $(85.42 \%)$ of the students get their information from other information sources like their families in the form of advice and $67.71 \%$ of health professionals get their information from their medical schools. The most frequently mentioned zoonotic diseases were Rabies 384(100 \%), followed by Anthrax 362(94.27\%), Teniasis 342 (89.06\%), Tuberculosis 340 (88.54\%) and Brucellosis 190(49.48\%) and $120(31.25 \%)$ mentioned other infectious diseases of zoonotic importance. The importance of veterinary public health in the overall public health institutions was assessed by looking at the responses to questions and shown that yet the public health institutions don't see the need of having veterinarians in the public health. In conclusion this study demonstrated that the awareness and use of inspected and packed animal products is relatively low that expose the people to risk of food borne pathogens and the awareness of health institutes on the importance of veterinary public health service is relatively low. The authors would like to recommend to the government and concerned bodies to raise the awareness of the public using the appropriate communication media, and to strengthen the contribution of public health veterinarians in the public health services for better community health.
\end{abstract}

Keywords: awareness, veterinarian, food borne zoonoses

http://dx.doi.org/10.4314/evj.v16i1.2 


\section{Introduction}

Foods of animal origin are among the favourite and commonly consumed nutrients by most human communities in the world. However, if they are not prepared and handled properly they lead to the cause of many food borne diseases (Avery, 2004). The most prevalent diseases transmissible from animals to man include, tapeworm, anthrax and bovine tuberculosis (FDRE - MoH, 2004). Veterinary medical practice is unique among the health professions in that its objectives are to enhance the health, care, productivity and well being of animals as well as to guarantee the safety of animal products used by people (Hendrix et al., 2005). The ultimate objective of veterinary medicine is to promote the well being and the quality of human life. Moreover, veterinary public health is a discipline which deals with the contribution and responsibility of veterinary medicine for the public health (Cosivi et al., 1999). Approximately four- fifth of all described agents of infections of human being are shared in nature with other vertebrate animals (Daszak et al., 2000). Many animal related problems, which negatively affect human health and economy exist in all countries of the world including zoonoses, food borne diseases and pollution of the environment from animal sources. Most of the agents associated with the current worldwide increase in cases of food borne diseases such as Salmonellosis, E. coli, Campylobacteriosis and Listeriosis are concerns especially in the developing world. In addition zoonoses like Rabies, Brucellosis, Bovine Tuberculosis, Cysticercosis, Hydatidosis, Taeniasis, Toxoplasmosis are yet uncontrolled diseases (WHO, 2002) which need the attention of-veterinary public health services. Generally in most cases these cannot be controlled without a full, multidisciplinary approach which includes public education and involvement as well. Hence, veterinary public health has become a much more active field of inquiry and is involved with human health than it was before. Furthermore veterinary public health activities involve a diverse range of functions within the public, which reflect the broad community interest between veterinary and human medicine (Christensen, 1996; King and Khabbaz, 2010). So far there is no documented evidence of the awareness and use of veterinary public health services and how far public health institutes are aware of the importance of veterinary public health service in maintaining the health of the community. The purposes of this study were therefore, to assess the awareness on food borne zoonosis and its relation with veterinary public health services. 


\section{Materials and methods}

\section{Study area and population}

This study was conducted in Addis Ababa and its surrounding districts (namely Holleta, Sebeta and Debre Zeit) from November 2008 to April 2009. The study population comprised of students of different educational level (elementary and high schools and graduates), human and animal health professionals and non health professionals and institutes. Addis Ababa and its surroundings have approximately 6 million people, 16 hospitals and more than 500,000 students at different level of education (personal communication). The participants were allowed to answer at that spot in order to have $100 \%$ response rate.

\section{Study design and sample size}

The survey was conducted to assess the awareness and use of veterinary public health services in and around Addis Ababa. Evaluation methods including a well designed interview and questionnaire were done. Stratified random sampling was considered based on educational level and profession. Accordingly, semi structured questionnaires supplemented with interview were administered to 576 people of whom 192 elementary and high school students, 192 graduates, and 96 health and 96 non health professionals were asked about their custom of consuming inspected, packed and or treated animal products, source of information about veterinary public health and knowledge of zoonotic diseases they knew. In addition, directors of 7 health institutions were interviewed regarding public health veterinarians in public health institutions.

\section{Data collection and analysis}

Data was collected using questionnaires and interviews to evaluate the degree of awareness and use of veterinary public health services. The data generated were entered to a MS-Excel-2007 program and were analysed by SPSS 18 version (2010) using descriptive statistics including chi square for possible explanation of associations. P-value of less than 0.05 was considered to be significant at $95 \%$ confidence interval.

\section{Results}

The use of inspected meat, pasteurized or boiled milk and packed honey across educational level and health related profession is shown in Table 1. The use of inspected animal products is found statistically different $(\mathrm{P}<0.05)$ among 
health and non health professionals while no difference is seen between students and graduates.

Table 1: Use of inspected/treated animal products by education level and profession in Addis Ababa and its surroundings.

\begin{tabular}{lccc}
\hline Category & \multicolumn{3}{c}{ Animal products } \\
\cline { 2 - 4 } & \multicolumn{1}{c}{ Milk } & Honey & Meat \\
\hline Educational level* & & & \\
$\quad$ Elementary and High school (n=192) & $174(90.62 \%)$ & $185(96.35 \%)$ & $59(30.72 \%)$ \\
$\quad$ Graduates (n=192) & $184(95.83 \%)$ & $190(98.95 \%)$ & $67(34.89 \%)$ \\
Profession** & & & $82(85.42 \%)$ \\
$\quad$ Health professionals $(\mathrm{n}=96)$ & $96(100 \%)$ & $90(93.75 \%)$ & $77(80.21 \%)$ \\
$\quad$ Non health professionals $(\mathrm{n}=96)$ & $69(71.88 \%)$ & $88(91.67 \%)$ &
\end{tabular}

Students, graduates, health and non health professionals get information about zoonotic diseases and veterinary public health services from different sources (Table 2). Hence, majority (85.42\%) of the students get the information from other information sources like their families in the form of advice and $67.71 \%$ of health professionals get from schools they attended during their medical education.

Table 2: Sources of information about zoonotic diseases to study participants by education level and profession in Addis Ababa and its surroundings.

\begin{tabular}{lcccc}
\hline Information source & \multicolumn{4}{c}{ Educational status of respondents } \\
\cline { 2 - 5 } & $\begin{array}{c}\text { Elementary } \\
\text { and high school } \\
\text { students }\end{array}$ & Graduates & $\begin{array}{c}\text { Non health } \\
\text { professionals }\end{array}$ & $\begin{array}{c}\text { Health } \\
\text { professionals }\end{array}$ \\
\hline Mass media* & $24(12.50 \%)$ & $56(30.73 \%)$ & $50(52.08 \%)$ & $10(10.42 \%)$ \\
Electronic media** & $0(0 \%)$ & $17(8.85 \%)$ & $21(21.88 \%)$ & \\
& & $17(17.71 \%)$ & & \\
School*** $^{* * 2}$ & $4(2.08 \%)$ & $47(24.45 \%)$ & $2(2.08 \%)$ & $65(67.71 \%)$ \\
Others $^{* * * *}$ & $164(85.42 \%)$ & $72(37.50 \%)$ & $27(28.13 \%)$ & $0(0.00 \%)$ \\
\hline
\end{tabular}

${ }^{*} \mathrm{P}>0.05,{ }^{* *} \mathrm{P}<0.05,{ }^{* * *} \mathrm{P}<0.05,{ }^{* * * * \mathrm{P}<0.05}$

The most frequently mentioned zoonotic diseases were Rabies 384(100 \%), followed by Anthrax 362(94.27\%), Teniasis 342 (89.06\%), Tuberculosis 340 (88.54\%), Brucellosis 190(49.48\%) and 120(31.25\%) mentioned other infectious diseases of zoonotic importance. Different questions were raised through 
interviewers to directors of the seven public health institutions about the contribution of public health veterinarian to promote the health of the public and the study found no public health veterinarian in health centres and hospitals contributing to public health (Table 3 ).

Table 3: Results of response by directors of public health institutes to questions on the importance of veterinary public health services in Addis Ababa and its surroundings.

\begin{tabular}{lcc}
\hline Key condition(questions) & \multicolumn{2}{c}{ Response } \\
\cline { 2 - 3 } $\begin{array}{l}\text { Presence interprofessional cooperation between veterinarians } \\
\text { and veterinary public health services providing centers }\end{array}$ & $1(14.28 \%)$ & $6(85.72 \%)$ \\
Presence of services to inspect food of animal origin. & $5(71.42 \%)$ & $2(28.58 \%)$ \\
Presence of health extension department on zoonotic diseases. & $3(42.85 \%)$ & $4(57.15 \%)$ \\
Presence of public health veterinarian in the institute & $0(0 \%)$ & $7(100 \%)$ \\
\hline
\end{tabular}

\section{Discussion}

The current study has disclosed that the use of inspected animal products is found statistically different $(\mathrm{P}<0.05)$ among health and non health professionals while no difference is seen between students and graduates. The habit of eating uninspected backyard slaughtered meat was also seen to be very high as reported in a previous study (Tamiru et al., 2008; Avery, 2004). This could be due to the low level of awareness of the public on the importance of using inspected meat because of cultural beliefs that raw meat is better than cooked one and the deeply established traditional habit of eating raw meat in the country. The use of either pasteurized or boiled milk is relatively higher in all segments of the study participants because of better awareness. However, the use of packed honey was significantly low in the study population. This could be because of the marketing and unavailability of packed and processed honey packing companies in the country and also low level of awareness of availability of packed products in supermarkets .

The majority elementary and high school students get the information about zoonotic diseases from their families in the form of advice while most health professionals get their information from medical schools they attended which justifies that health professionals have better awareness about zoonotic diseases. It is shown that health professionals have better know how as compared to non health professionals and students' response is used to access 
information about what families of school aged children. However it does not tell their preference as they rarely prefer what to eat. Even though, most of these people have awareness on zoonotic disease and the hazard that could emerge from consumption of uninspected and untreated animal products, it seems that they couldn't clearly understand the routes of transmission of those zoonotic diseases. One interesting thing to consider here is that the degree of using inspected or treated animal products goes better as educational level and accessibility to media and health related education advances (Table 2). This study indicated that public health service providing centres have low level of awareness on the importance of veterinary public services, which is consistent with the report by Ketema, (2010). Veterinarians, because of their knowledge of animal diseases and food production, as well as their training in ecological, economic and human cultural issues, have become leaders in developing and implementing new methods of promoting sustainable public health which consider the ecosystem that are culturally feasible and economically realistic. Veterinary input and major disease control programmes have resulted in the successful eradication of many zoonotic diseases e.g. Bovine Tuberculosis, Brucellosis, Rabies, Trichinellosis and Echinococcosis in developing countries (King and Khabbaz, 2010). The most poignant example is Hong Kong with the control of avian influenza envied in the region that has been a direct result of veterinary advice and policy implementation (King, 2006; Waltner-Toews, 2009). The placement of public health veterinarian in public health giving centres is negligible and even the public heath personnel have low level of awareness on the importance of public heath veterinarians in maintaining public health. Furthermore, there is no structural organization of veterinary public health units in Ethiopia. According to the WHO and FAO joint report there is a recommendation about importance of placing veterinarians in the public health sector for zoonotic diseases control prevention, inspection of food of animal origin hygiene, consumer protection and environment protection (King and Khabbaz, 2010). Therefore, based on this study, the authors would like to recommend the government and concerned institutions to campaign to raise the awareness of the public using the appropriate communication media, and to strengthen the contribution of public health veterinarians in the public health for better community health.

The interview with the directors of public health institutions was an important indicator of lack of participation of veterinarians in public health departments. Graduate and high school information sources a means probably differentiate the power to apply what is transmitted on mass media and it is believed 
that elementary and high school students are under their family food item and quality choice. In addition, information from medical school for health professionals was considered important in their selection of inspected meat and knowledge of zoonotic disease. The significance of these needs to be reiterated: so therefore it is important that this be considered when educating health professionals and the directors of the public health schools increase the involvement of veterinarians in public health improvement. Further studies are recommended to see the importance of veterinary public health services from one health point of view.

\section{References}

Avery A., 2004. Red meat and poultry production and consumption in Ethiopia and distribution in Addis Ababa. Borlaug Ruan World Food Prize. International Livestock Research Institute Addis Ababa, Ethiopia.

Christensen S.G., 1996.Veterinary medicine- Impacts on human health and nutrition in Africa: Inproceeding of an international conference held at ILRI, Addis Ababa, Ethiopia. August 27-31, 1995.

Cosivi O. and Meslin F.X., 1999. Future trends in veterinary public health. World Veterinary Association Bulletin 16, 2-9.

Daszak, P, Cunningham, A. A, Hyatt, A.D. , 2000. Emerging Infectious Diseases of Wildlife-Threats to Biodiversity and Human Health. Science, 287, 443

FDRE- MoH (Federal democratic republic of Ethiopia- Ministry of Health), 2004. Food Hygiene and Safety Measures Extension Package.

Hendrix C.M., McClelland C.L, Thompson I., Maccabl A. T., Hendrix, C.R., 2005. An inter194 professional role of veterinary medicine in human health promotion and disease prevention in; Journal of inter-professional care, 19.

Ketema Tafess, 2010. Assessments of the awareness the community about zoonotic diseases, habit of consuming raw animal products and the importance of veterinary public health in the health institutes. Research work submitted to Gondar university research and publication office, Gonder, Ethiopia.

King J.L., 2006. Veterinary Medicine and Public Health at CDC. Office of the Director, National Centre for Zoonotic, Vector-Borne, and Enteric Diseases. Atlanta. 
King, Lonnie, Khabbaz, Rima. 2003. Converging Issues in Veterinary and Public Health. Emerging Infectious Diseases, 9, 4.

Tamiru Negash, Getachew Tilahun and Medhin G., 2008. Seroprevalence of Toxoplasma gondii in Nazareth town, Ethiopia. East African Journal of Public Health, 5, 3.

Waltner-Toews D., 2009. Eco-Health: A primer for veterinarians. Canadian Veterinary Journal, 50, 519-521.

WHO, 1975. The veterinary contribution to public health practice report of a joint FAO/ WHO Expert committee on veterinary public health. Technical report series 573 , WHO, Geneva.

WHO, 2002. Future trends in Veterinary public health Technical report series. 907, Report of a WHO Study Group, Geneva, 1-7. 